\title{
Regime-Switching Foreign Exchange Rate Exposures of the Asian Emerging Markets
}

\author{
Chunhuang Liao \\ Economics \& Management College \\ Zhaoqing University \\ Zhaoqing, China
}

\begin{abstract}
The purpose of this study is to improve the traditional linear measuring framework of market-level foreign exchange rate exposure by considering the long-run cointegration relationship with error correction and panel smooth transition function to show the short-run nonlinear regime-switching feature of exposure. The unique feature of the nonlinear exposure model in this paper in contrast to previous studies is that the exposure is measured under the framework of PSTR-ECM with consideration of linking the stock, the exchange rate, and the interest rate together by introducing transition variable which represents investors' expectation of the financial markets. Three alternative transition variables were considered, including the CBOE Volatility Index, the long-run and short-run interest rate spread of US bonds, and that of China bonds, respectively. Finally, it is found that the Asian emerging markets face parity risks of regime-switching foreign exchange rate exposures against the USD and the CNY.
\end{abstract}

Keywords-exchange rate exposure; threshold; VIX; interest rate spread; PSTR-ECM

\section{INTRODUCTION}

The U. S. market and the China market are two largest economies in the world, and they are major trading partners of the Asian emerging economies. These two large economies have promoted prosperity and economic growth to these emerging markets in recent decades by a lot of amount of export and import. The typical representative Asian emerging markets (hereafter, AEM) in this region include Hong Kong, Indonesia, South Korea, Malaysia, Philippine, Singapore, Thailand, and Taiwan. However, under recent trade friction between the United States and the China (US-China trade friction), appreciation of US dollar (USD) and depreciation of China Yuan (CNY) becomes a critical concern and reallocates asset value of the AEM, this political event disturbs original balance of intra-Asian economies and causes these markets to face dramatic exchange rate exposure risks.

For the importance of the U. S. market, it has always been the main export area of the AEM. With relative advantages of cheap raw materials, labor and land costs, as well as inexpensive local currencies, the AEM has been able to export cheap commodities to the U. S. market for a long time and in large quantities with competitive price advantage, and earn foreign exchange to import some advanced capital equipment. As such, the U. S. market is a critical export market of the AEM. Consequently, the appreciation and depreciation of the USD often affects the international competitiveness of the AEM so that the dollardenominated exchange rate exposure is one of the important decision-making bases for the AEM central banks and enterprises.

For the importance of the Mainland China market, it has always been one of the critical export and import area of the AEM. In the past, the Mainland China is similar to the AEM in that it has cheap raw materials, labor and land costs, as well as cheap currency. Therefore, the Mainland China has been an international trade competitor of the AEM. However, in recent years, with China's high economic growth and improvement of people's consumption capacity, the Mainland China market gradually becomes an important export area of the AEM. Based on increasingly bilateral trade relationship between the Mainland China and the AEM, the CNY-denominated exchange rate exposure has begun to exert an important influence on the AEM market.

Under such situation, the AEM faces "parity risk" of foreign exchange rate exposures due to appreciation or depreciation of the USD and that of the CNY. When the USD appreciates against the AEM's home currencies, asset value of company is devalued in terms of local currency, causing a decline of stock price. On the other hand, when the CNY depreciates against the AEM's home currencies, the export of China becomes more competitive, and it brings great pressure to AEM's export manufacturers. As a result, AEM's companies face another foreign exchange exposure risk coming from the $\mathrm{CNY}$.

Overall, how to correctly deal with foreign exchange risk is a key problem on which the AEM faces. Nonetheless, our understanding of the mechanism of exchange rate exposure is still incomplete and empirical research is mixed at best (Muller \& Verschoor, 2006). Further investigation is worthwhile, especially under background of the recent USChina trade friction which causes the original ordered AEM markets to alter.

This paper extends the existing literature in the following ways. First, this study proposes the PSTR-ECM for measuring the varying market exchange rate exposures. This approach has the advantage of considering the cointegration relationship between the stock and the exchange rate markets 
2006; Dominguez \& Tsar, 2006; Béreau et al., 2010), varying over time (Williamson, 2001; Dominguez \& Tsar, 2006; Muller \& Verschoor, 2006; Parsley \& Popper, 2006; Priestley \& Ødegaard, 2007; Chue \& Cook, 2008; Hutson \& O'Driscoll, 2010), and the exchange rate might change over different regimes (Béreau et al., 2010). This implies that the traditional methods of measuring constant and linear exposure may be inappropriate (Priestley \& Ødegaard, 2007).

Third, given that the exposure of exchange rate is varying, and the classical exposure model is unable to formulate the variation of exposure, hence, it causes empirical studies have to subdivide their entire sample periods into multi-periods and estimate the exposures repeatedly.

Jorion (1990) refined the linear regression model for measuring the exposures by including a stock market index in the regression model, because exchange rates and stock prices may move together. The role of the stock market index here is to serve as a control variable which controls for the macroeconomic effects of exchange rate movements (Hutson \& O'Driscoll, 2010). Nevertheless, exchange rates and stock prices may move together in the long run, but they may not always be in the short run. When the stock and the exchange rate markets are in disequilibrium in the short run, deviation or misalignment happens to some extent.

Although the linear exposure model was once refined by Jorion (1990), a lot of empirical studies have still pointed out that the foreign exchange rate risk on firm value can be found for only a small number of firms, and this phenomenon is known as the "exposure puzzle" (Bartram, 2004). In order to acquire more evident effects of the exposures, Williamson (2001) cautioned that using the aggregation of exchange rate can mute the effect of an exchange shock on firm value. This implies that using a single bilateral exchange rate for measuring exposure might be better than using a weighted exchange rate. This argument is supported by Bartram (2004) who documented that the aggregation of several currencies may lead to the diversification effect, causing the exposures to be insignificant. Further, this argument is also consistent with the finding of Priestley \& Ødegaard (2007) in that they showed there is little evidence that industries are exposed to a currency basket. Thus, using a specific exchange rate for measuring exposures seems to be a good choice for the empirical study of exposures.

Moreover, for a more complete insight into exposures, using a long sample period seems to be necessary. Williamson (2001) supported this point and argued that a long sample period is necessary to incorporate possible changes in the business cycle or market fundamentals. More evidence to support this argument can be found in Koutmos \& Martin (2003), who concluded that using short horizons may not be sufficient enough to capture exchange rate exposures, and Muller \& Verschoor (2007), who found the magnitude of firms' exchange rate exposure coefficients becomes larger as the horizon lengthens. Thus, it is suggested that the sample period should be long enough when measuring exposures. Nevertheless, the exposures are time varying. In order to capture more information about 


\section{A. The Linear Error Correction Model}

varying exposures, a common approach in empirical studies is to subdivide the sample period and observe the changes of exposures (for instance, Williamson, 2001; Bartram, 2004; Priestley \& Ødegaard, 2007; Chue \& Cook, 2008). However, splitting the sample period into multi-periods is equivalent to shortening each time horizon for measuring the exposures; unfortunately, this may be not sufficient enough in each time horizon to capture the exchange rate exposures, as Koutmos \& Martin (2003) suggested. As such, lengthening and shortening the sample period causes contradiction.

In light of some shortcomings of the traditional linear and constant exposure measurements, recent studies have reconsidered the behavior of exchange rate in a nonlinear manner (Bartram, 2004; Priestley \& Ødegaard, 2007; Muller \& Verschoor, 2007; Béreau et al., 2010). The nonlinear behavior of exchange rate can be explained by certain factors (see inter alia Bartram, 2004 and Béreau et al., 2010). For instance, the effects of small and large exchange rate changes (Bartram, 2004), depreciating or appreciating currency (Priestley \& Ødegaard, 2007), heterogeneity of buyers and sellers, or heterogeneity of central banks' interventions (Béreau et al., 2010) may all lead to varying firm behavior. These authors addressed the behavior of exchange rate in a nonlinear manner and got some significant evidence; thus, nonlinear exposure is worthy of further reconsideration.

Although the exchange rate exposures have been extensively explored and discussed, there is one important argument need to be considered. Levi (1994) had suggested modeling the exposures by special variable-coefficients econometric techniques for preventing the problem of volatility of exposures which leads to insignificant exposures. To circumvent the problem and make the classical model of Adler \& Dumas (1984) more complete, this study considered Levi's suggestion above and reconstructed the linear exposure framework by the method of panel cointegration with error correction model, and extended the traditional model to a nonlinear model with the Panel Smooth Transition Regression (PSTR) proposed by González et al. (2005, 2017). Finally, the PSTR-ECM model is constructed in this paper to improve the exposure measuring model.

\section{MODEL SPECIFICATION}

According to Adler \& Dumas's (1984) exposure model, the market-level foreign exchange rate exposure with parity risks (Solakoglu, 2010) for the AEM can be quantified by measuring the sensitivity of stock returns to foreign exchange rate changes, formulated as:

$$
R_{M, t}^{i}=\mu_{i}+\beta_{2}^{i} R_{U S D, t}^{i}+\beta_{3}^{i} R_{C N Y, t}^{i}+\varepsilon_{i, t}
$$

where $R_{M, t}^{i}$ is the individual stock market return rate of the AEM, $R_{U S D, t}^{i}$ and $R_{C N Y, t}^{i}$ are the return rate of exchange of individual local currency in terms of the USD and that of the CNY, respectively. Coefficients of $\beta_{2}^{i}$ and $\beta_{3}^{i}$ are marketlevel foreign exchange rate exposure risk of local currency relative to the USD and the CNY, respectively. These coefficients show the sensitivity of stock returns to unanticipated exchange movements.
Model (1) simply links the stock and the foreign exchange rate markets without consideration of the long-run equilibrium relationship between both markets and without clearly identifying short-run exposures. For instance, when the stock market is more efficient than the exchange rate market because the latter is intervened with by a central bank to maintain stable exchange rate policy in the short run, the situation of disequilibrium between both markets occurs; and vice versa. In such circumstances, the stock price might reveal firm's future value more truly, but the exchange rate might be distorted. As such, the exposures measured under such a situation may be economically or statistically biased. Thus, in order to prevent biased exposures, it can reformulate (1) as (2) and (3) in the following:

$$
\begin{aligned}
& R_{M, t}^{i}=\mu_{i}+\beta_{1} z_{t-1}^{i}+\sum_{k=0}^{k^{*}} \beta_{2 k} R_{U S D, t-k}^{i}+\sum_{k=0}^{k^{*}} \beta_{3 k} R_{C N Y, t-k^{*}}^{i} \\
&+\varepsilon_{i, t} \\
& \ln \left(M_{t}^{i}\right)=\alpha_{0}^{i}+\alpha_{1} \ln \left(U S D_{t}^{i}\right)+\alpha_{2} \ln \left(C N Y_{t}^{i}\right)+z_{t}^{i}
\end{aligned}
$$

Where $M_{t}^{i}$ is individual stock market index, $U S D_{t}^{i}$ and $C N Y_{t}^{i}$ are bilateral exchange rates of local currency in terms of the USD and that of the CNY, respectively, $\alpha$ and $\beta$ are coefficients to be estimated, and $\mathrm{k}$ is lagged length. Modeling (3) first ensures the long-run cointegration relationship prior to further analysis of the exposure measurement; $z_{t}^{i}$ is an error term, indicating temporary misalignment or deviation away from the long-run equilibrium relationship. In theory, mean-reversion behavior occurs due to cointegration and expectation of the error term $\mathrm{E}\left(z_{t-1}^{i}\right)$ equals zero, then the error correction model (ECM) of (2) reduces to (1) when in equilibrium and with no lagged terms. Technically, the role of the misalignment term $z_{t-1}^{i}$ of (2) is similar to including a control variable in the classical model of Adler \& Dumas (1984), as Jorion (1990) did. On the other hand, to test the significance of exposures, $\beta_{2 k}$ and $\beta_{3 k}$, is equivalent to testing the Granger-causality, as in (2). In terms of the meanings, the changes of stock market value are influenced by considering both the magnitude of past deviation from the long-run equilibrium relationship and the contemporaneous exchange rate changes. When there is a large deviation in the previous period, the deviation might be expected to converge in the current period and the contemporaneous exposure risk might be affected. Thus, the exposures measured by (2) are short-run exposure risks.

\section{B. The Panel Smooth Transition Regression with Error Correction Model}

Nonetheless, adjusting to the equilibrium relationship takes time, and the exposure may vary over time (Adler \& Dumas, 1984). To better match practical situation mentioned, one can consider the proposition of variable-coefficient specification documented by Levi (1994) for preventing problems of volatility of exposure which force the exposure to be statistically insignificant, leading to the erroneous conclusion of little exposure. Thus, (2) can be modified by the PSTR-ECM framework as (4) and (5) in the following: 
Dumas (1984), the PSTR-ECM exposure model is much more generalized and it takes the variation of exposures into consideration. When the smooth transition in (4) is insignificant, then the exposures, $\beta_{2 k, t}^{h}$ and $\beta_{3 k, t}^{h}$, in (4) reduce to constants, $\beta_{2 k}$ and $\beta_{3 k}$, as in (2). Therefore, (4) is a generalization of (2) and (2) is an extension of (1). The classical model of (1) is a special case of (4) when it is in equilibrium and the exposure is constant.

\section{EMPIRICAL RESULTS}

$$
g\left(S_{t} ; \gamma, c\right)=\left[1+\exp \left(-\gamma \prod_{l=1}^{m}\left(S_{t}-c_{l}\right)\right]^{-1} \text { for } m=1,2\right.
$$

Where $g\left(S_{t} ; \gamma, c\right)$ is a continuous function of the transition variable $S_{t}, \gamma$ is a slope parameter which determines the smoothness of the transitions, $c$ is a location, and $m$ is the number of locations. In practice it is sufficient to consider $m=1$ or $m=2$, as González et al. (2005, 2017) proposed. Moreover, this study only considers there is one transition variable in (4) and (5) to avoid excessively large models.

Specifications of (3), (4) and (5) involve the market exposure model with the PSTR-ECM framework with only one transition function $g\left(S_{t} ; \gamma, c\right)$ and two switching regions. The procedure of the PSTR model consists of specification, nonlinear estimation, and evaluation stages; homogeneity test for nonlinearity, the sequence of homogeneity tests for selecting number of regimes, and the remaining heterogeneity tests have to be done.

Further simplification of the market-level exposures can be expressed as follows:

$$
\beta_{p k, t}^{h}=\beta_{p k}+\beta_{p k}^{*} \cdot g\left(S_{t} ; \gamma, c\right) ; p=1,2,3
$$

The superscript $h$ in (6) is to show the heterogeneity of the coefficients. For (6), the heterogeneous coefficients, $\beta_{1 k, t}^{h}$, of the error correction term should be negative at least in one regime to show convergence due to the long-run equilibrium relationship and adjust smoothly to the equilibrium. The heterogeneous coefficients of $\beta_{2 k, t}^{h}$ and $\beta_{3 k, t}^{h}$ are the estimated market-level exchange rate exposures based on a specific threshold variable $S_{t}$. Since values of the threshold variable $S_{t}$ varies over time, consequently, the heterogeneous market exposures, $\beta_{2 k, t}^{h}$ and $\beta_{3 k, t}^{h}$, are time-varying based on changes of the transition variable. Given that the marketlevel exposures measured contain the characteristic of variation with smooth regime-switching behavior by the smooth transition function, there is no need to split the sample period and re-estimate the exposures repeatedly.

Further, Bartram (2004) documented that small foreign exchange rate changes may be reflected less in stock prices, while large foreign exchange rate changes, however, may impact firm value more strongly and reveal the actual relationship. Thus, threshold effects may exist to reflect the large exposures which switch from one small regime to another large regime when the unexpected exchange rate changes are large enough. The existence of threshold effect implies that the exposures are regime-switching.

Lastly, comparing the PSTR-ECM exposure model with the classical linear exposure model proposed by Adler \&

\section{A. Data Descriptions}

The AEM investigated in this study includes Hong Kong (HK), Indonesia (ID), South Korea (KR), Malaysia (MY), Philippine (PH), Singapore (SG), Thailand (TH), and Taiwan (TW) 1. The sample period spans from 2010:01:03 to 2019:09:29 with 508 weekly observations in each series of variables, including stock market indices and corresponding return rates $\left(R_{M}\right)$, foreign exchange rates (the USD and the $\mathrm{CNY}$ ) and corresponding return rates $\left(R_{U S D}\right.$ and $\left.R_{C N Y}\right)$, CBOE volatility index (VIX), interest rate spread of 10 -year and 1-year US bonds $\left(I R S_{U S}\right)$ and interest rate spread of 10year and 1-year China bonds $\left(I R S_{C N}\right)$. The exchange rate USD denotes the amount of local currency against per US dollar, and that of $C N Y$ denotes the amount of local currency against per Renminbi.

All data are nominal and in weekly frequency for consistency, and the raw data can be downloaded from the websites of https://www.investing.com or the https://cn.investing.com to reproduce the results of investigation in this study. TABLE I presents descriptive statistics of the AEM panel data investigated.

\section{B. Panel Cointegration Tests}

For panel unit root test, the panel series of $R_{M}, Z_{t-1}$, $R_{U S D}, R_{C N Y}$, VIX, IRS $S_{U S}$, and $I R S_{C N}$ are found to reject null hypothesis of unit root and all series are stationary. For panel cointegration test, the variables in (3) of $\ln \left(M_{t}^{i}\right), \ln \left(U S D_{t}^{i}\right)$, and $\ln \left(C N Y_{t}^{i}\right)$ present cointegration by the Pedroni Residual Cointegration Test and the Kao Residual Cointegration Test. So far, the data are suitable for further analysis. To save space, the results are omitted here and can be offered. (See "Table I")

\section{Results of the Panel Regression with Error Correction Model}

Next, the panel regression with error correction model of (2) is conducted. "Table II" presents the outputs of panel regression under situations of no-effects, fixed effect, and random-effect for comparisons.

As seen in the "Table II", the coefficients and the Fstatistic in the three cases are all significant. In the case of no-effects, the coefficient $\beta_{1}$ of $\mathrm{Zt}-1$ is -0.011 where the sign is minus implies meeting the requirement of error correction model. The coefficient $\beta_{2}$ of RUSD, $\mathrm{t}$ is -1.0567 where the

Dominguez and Tsar (2006) suggested that small firms are more likely to be exposed. Therefore, this study chose smaller markets of the AEM for investigation of market-level exposures, excluding large economies of China, India and industrialized Japan. 
promotes net-export to the Mainland China and increases corporate profits. Overall, it can be seen that the exposure against the USD is minus and the exposure against the CNY is plus for the AEM. depreciation of assets in terms of local currency. The coefficient $\beta_{3}$ of $\mathrm{RCNY}, \mathrm{t}$ is 0.1575 and the sign is plus implies that the appreciation of CNY relative to local currency facilitates the AEM stock returns to rise because it

TABLE I. DESCRIPTIVE STATISTICS FOR PANEL DATA

\begin{tabular}{|c|c|c|c|c|c|c|c|}
\hline Statistic & $R_{M}$ & $z_{t-1}$ & $R_{U S D}$ & $\boldsymbol{R}_{C N Y}$ & VIX & $I R S_{U S}$ & $I R S_{C N}$ \\
\hline Mean & $0.09 \%$ & $-0.02 \%$ & $0.02 \%$ & $0.01 \%$ & 16.78 & $1.69 \%$ & $0.73 \%$ \\
\hline Median & $0.21 \%$ & $1.17 \%$ & $0.01 \%$ & $0.01 \%$ & 15.36 & $1.72 \%$ & $0.66 \%$ \\
\hline Maximum & $10.49 \%$ & $36.24 \%$ & $5.42 \%$ & $5.43 \%$ & 43.05 & $3.52 \%$ & $2.17 \%$ \\
\hline Minimum & $-11.27 \%$ & $-66.18 \%$ & $-8.72 \%$ & $-8.55 \%$ & 9.14 & $-0.27 \%$ & $-0.38 \%$ \\
\hline Std. Dev. & $2.00 \%$ & $13.04 \%$ & $0.79 \%$ & $0.79 \%$ & 5.73 & $0.89 \%$ & $0.42 \%$ \\
\hline Skewness & -0.43 & -0.79 & -0.21 & -0.18 & 1.75 & -0.11 & 1.14 \\
\hline Kurtosis & 5.34 & 5.55 & 11.22 & 10.35 & 6.87 & 2.30 & 4.37 \\
\hline Jarque-Bera & 1051 & 1522 & 11463 & 9173 & 4619 & 92 & 1196 \\
\hline Probability & 0.00 & 0.00 & 0.00 & 0.00 & 0.00 & 0.00 & 0.00 \\
\hline Observations & 4064 & 4064 & 4064 & 4064 & 4064 & 4064 & 4064 \\
\hline
\end{tabular}

a. Note: Symbols of $R_{M}$ is return rates of stock market index, $R_{U S D}$ and $R_{C N Y}$ are return rates of foreign exchange of local currency relative to the USD and the CNY, respectively. $Z_{t-1}$ is the deviation from the long-run equilibrium of equation (3). VIX is the CBOE volatility index. IRS $S_{U S}$ and $I R S_{C N}$ are the interest rate spreads of US bonds and that of China bonds, respectively, i.e., yield of 10-year bond minus yield of 1 -year bond.

TABLE II. ESTIMATED EXPOSURES BY THE LINEAR REGRESSION WITH ERROR CORRECTION MODEL

\begin{tabular}{|c|l|l|l|}
\hline Variable & \multicolumn{1}{|c|}{ No-effects } & \multicolumn{1}{|c|}{ Fixed-effect } & \multicolumn{1}{|c|}{ Random-effect } \\
\hline Constant & $0.0010^{* * *}$ & $0.0010^{* * *}$ & $0.0010^{* * *}$ \\
\hline $\boldsymbol{\beta}_{\mathbf{1}}$ & $-0.0110^{* * *}$ & $-0.0109^{* * *}$ & $-0.0110^{* * *}$ \\
\hline $\boldsymbol{\beta}_{\mathbf{2}}$ & $-1.0567^{* * *}$ & $-1.0581^{* * *}$ & $-1.0567^{* * *}$ \\
\hline $\boldsymbol{\beta}_{\mathbf{3}}$ & $0.1575^{* * *}$ & $0.1562^{* * *}$ & $0.1575^{* * *}$ \\
\hline$A d j-R^{2}$ & 0.1405 & 0.1406 & 0.1405 \\
\hline$F$-statistic & $222.44^{* * *}$ & $67.50^{* * *}$ & $222.44^{* * *}$ \\
\hline$A I C$ & -5.1334 & -5.1319 & - \\
\hline$S B C$ & -5.1272 & -5.1148 & - \\
\hline Durbin-Watson & 2.1476 & 2.1517 & 2.1476 \\
\hline
\end{tabular}

a. Note: Symbols of *,**, and $* * *$ indicate significant under $10 \%, 5 \%$, and $1 \%$ significance levels, respectively. The redundant fixed-effects test shows $\chi 2(7)$ is 7.5680 and insignificant. The Hausman test shows $\chi^{2}(3)$ statistic is 7.1951 and insignificant. The lagged length $\mathrm{k}=0$.

Although the results are significant and the outcomes are in line with actual circumstance observed in the world, unfortunately, the information and the dynamic adjustment process of exchange rate exposures revealed in the "Table II" is far from enough.

\section{Results of the PSTR-ECM}

Following is results of the estimated PSTR-ECM for three alternative cases, "Table III", where the transition variables are VIX, IRS $S_{U S}$, and $I R S_{C N}$, respectively, showing that the exposures have the feature of regime-switching with respect to specific transition variable.

First of all, as can be seen in the TABLE III, in the case 1 where the transition variable is VIX $X_{t}$, the results show that there is one $(\mathrm{m}=1)$ monotonically increasing transition function with slope $\gamma=2.6364$ and one threshold locates at the value of 23.602. As such, it forms two different regimes within which the sensitivity of exposure changes gradually as a function of the transition variable $V I X_{t}$. When the value of VIX $X_{t}$ is smaller than the threshold value of 23.602 , the exchange rate exposure against the USD, $\beta_{2, t}^{h}$, locates mainly in the lower regime (regime 1) with a significant value of 1.1464. On the other hand, the exchange rate exposure against the $\mathrm{CNY}, \beta_{3, t}^{h}$, locates mainly in the lower regime with a significant value of 0.464 . In contrast, when the value of VIX $X_{t}$ is greater than the threshold value of 23.602 , the exposure $\beta_{2, t}^{h}$ locates mainly in the upper regime (regime 2 ) with a significant value of 0.5453 , and that of the exposure $\beta_{3, t}^{h}$ is -1.5515 . Thus, when the value of VIX $t$ is small, the exposure behaves in one way in the lower region, while the value of VIX $X_{t}$ becomes large enough, the exposure behaves in another way in the upper region.

"Fig. 1" depicts the corresponding transition function where the threshold variable is VIX $X_{t}$. As can be seen in the "Fig. 1", the transition function of $g\left(V^{\prime} X_{t} ; 2.6364,23.602\right)$ is normalized and bounded between zero and one. These two extreme values are associated with the exposure of $\beta_{2, t}^{h}$ which switches from the negative regime of -1.1464 to the positive regime of 0.5453 significantly, and associated with the exposure of $\beta_{3, t}^{h}$ which switches from the positive regime of 0.464 to the negative regime of -1.5515 significantly. 
The lower regime of the exposure $\beta_{2, t}^{h}$ against the USD is significant at the value of -1.3211 , but the upper regime is not significant, as can be seen in the "Table III". For the exposure of $\beta_{3, t}^{h}$ against the CNY, two regimes are found and significant at 1.3125 and -1.5228 , respectively. As such, the exposure of $\beta_{3, t}^{h}$ is regime-switching with the transition variable of $I R S_{C N, t}$. Lastly, "Fig. 3" plots the corresponding symmetric transition function of $g\left(I_{R N, t} ; 188600,0.6 \%, 0.6 \%\right)$.

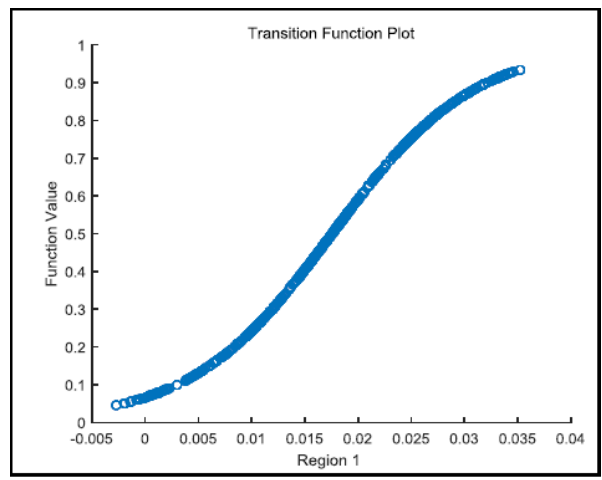

Fig. 2. Transition function where $S_{t}$ is $I R S_{U S, t}$.

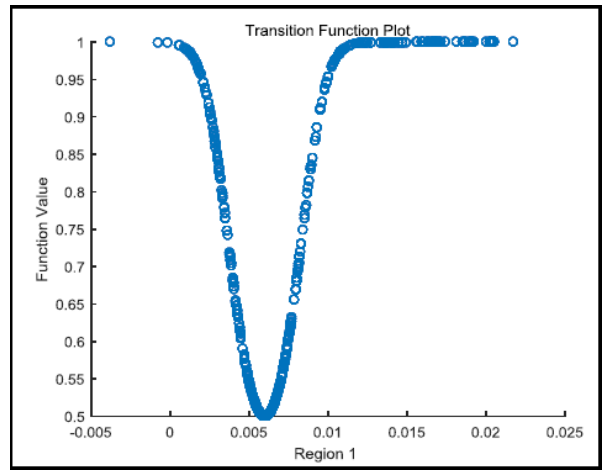

Fig. 3. Transition function where $S_{t}$ is $I R S_{C N, t}$.

\section{E. Results of Robustness Check}

For robustness check, in consideration of suggestion by Koutmos \& Martin (2003) and Muller \& Verschoor (2007) in that foreign exchange rate risk becomes more evident as the return horizon lengthens. Therefore, it seems unsuitable to split the sample period for checking robustness; instead, this study used the lagged terms of $V I X_{t-1}$ and $I R S_{U S, t-1}$, respectively, as alternative transition variables to demonstrate possible remaining regime-switching effects due to capital market imperfections by which buyers and sellers are constrained. As such, there is possibility of that the lagged terms of $V I X_{t-1}$ and $I R S_{U S, t-1}$ might have remaining transition effect on the exposure to some extent due to market imperfection.

In order to save space in this subsection, results of the homogeneity test for nonlinearity, the sequence of homogeneity tests for selecting number of regimes, and the remaining heterogeneity tests were omitted and can be offered upon request. 


\section{DISCUSSIONS ON THE TRANSITION VARIABLES}

"Table IV" presents parameters of final results for the robustness test. In the case 4 where the transition variable is $V I X_{t-1}$, the coefficient $\beta_{1, t}^{h}$ is significant at the value of 0.0109 where the sign is minus to show error correction. The exposures of $\beta_{2, t}^{h}$ and $\beta_{3, t}^{h}$ are significant at the values of 1.2621 and 0.5551 , respectively, in the regime 1 where the value of $V I X_{t-1}$ is smaller than the threshold value of 24.2881. In contrast, the exposures of $\beta_{2, t}^{h}$ and $\beta_{3, t}^{h}$ switch from the regime 1 to the significant regime 2 of 1.1431 and 1.9873, respectively, where the transition variable $V I X_{t-1}$ is greater than 24.2881. "Fig. 4" and "Fig. 5" depicts the corresponding transition function of $g\left(V_{I X-1} ; 0.4210,24.2881\right)$.

TABLE IV. ESTIMATED EXPOSURES OF THE PSTR-ECM FOR ROBUSTNESS TEST

\begin{tabular}{|c|c|c|c|}
\hline Parameter & regime 1 & regime 2 & transition function \\
\hline \multicolumn{4}{|c|}{ Case 4: Transition variable is $V I X_{t-1}$} \\
\hline$\beta_{1, t}^{h}$ & $-0.0109^{* * * *}$ & -0.0037 & \multirow{3}{*}{$\begin{array}{l}\gamma=0.4210 \\
c=24.2881\end{array}$} \\
\hline$\beta_{2, t}^{h}$ & $-1.2621^{* * *}$ & $1.1431^{* * *}$ & \\
\hline$\beta_{3, t}^{h}$ & $0.5551^{* * *}$ & $-1.9873^{* * *}$ & \\
\hline \multicolumn{4}{|c|}{ Case 5: Transition variable is $I R S_{U S, t-1}$} \\
\hline$\beta_{1, t}^{h}$ & $-0.012^{* * *}$ & 0.0029 & \multirow{3}{*}{$\begin{array}{l}\gamma=110.7535 \\
c=2.11 \%\end{array}$} \\
\hline$\beta_{2, t}^{h}$ & $-1.5528^{* * *}$ & $1.6804^{* * *}$ & \\
\hline$\beta_{3, t}^{h}$ & $1.2693^{* * *}$ & $-3.1161^{* * *}$ & \\
\hline
\end{tabular}

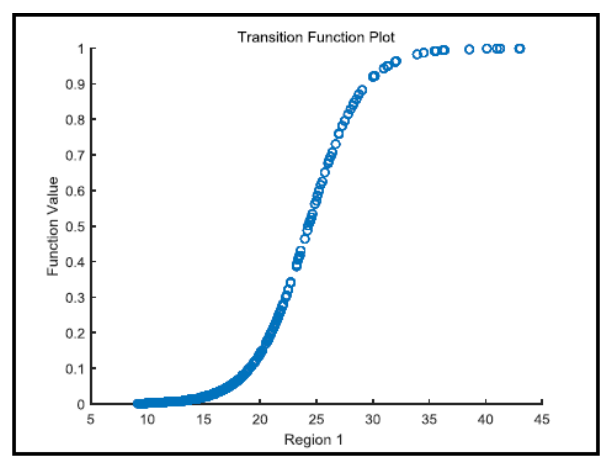

Fig. 4. Transition function where $S_{t}$ is $V I X_{t-1}$.

For another alternative transition variable $I R S_{U S, t-1}$, details of estimated parameters can be found in the case 5 of the TABLE IV. For saving space, similar description was omitted. Fig. 5 depicts the corresponding transition function of $g\left(I R S_{U S, t-1} ; 110.7535,2.11 \%\right)$. Finally, in this case, it can be seen that the exposures of $\beta_{2, t}^{h}$ and $\beta_{3, t}^{h}$ are regimeswitching with the lagged term $I R S_{U S, t-1}$.

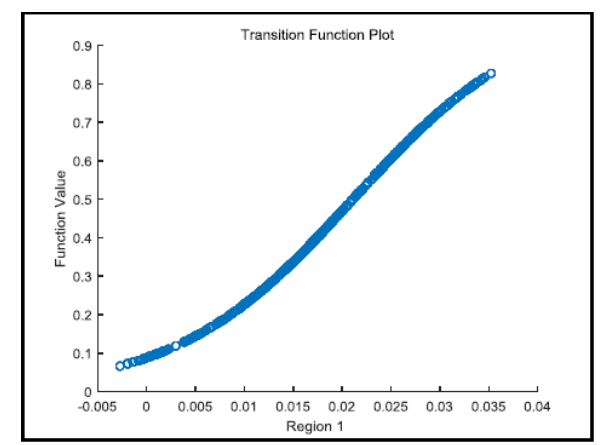

Fig. 5. Transition function where $S_{t}$ is $I R S_{U S, t-1}$.
The usage of the three alternative transition variables of $V I X, I R S_{U S}$, and $I R S_{C N}$ in this study has several meanings:

In the real world, the stock market, the foreign exchange market and the bond market are interconnected. Each market is hard to ignore changes of other financial markets and to move independently by its own. Therefore, the introduction of the three alternative transition variables of $V I X, I R S_{U S}$, and $I R S_{C N}$ into the PSTR-ECM framework in this study are complementary for other possible variables which might be neglected.

From the model (2) of Adler \& Dumas (1984), it is obvious that the exposure is measured under the model of linking the stock market and the foreign exchange market. However, it ignores the variable of interest rate of bond market. To isolate the bond market independently from the equation (2) seems not quite meet the situation observed in the real world. Therefore the model proposed by Adler \& Dumas (1984) is a simple case without considering the bond market.

When the transition variable is the interest rate spread, it can be seen that the stock market, the foreign exchange market and the bond market are linked together by the equations of (4) and (5). Due to a much more simultaneous consideration of changes of the three markets together when measuring exposures, the PSTR-ECM framework conducted in this study is more comprehensive and objective.

The commonality of the three alternative transition variables is that they all reveal investors' expectations of the present state relative to the future state of economies and financial markets.

For further explanations of the commonality, first, for the VIX observed, it is often low when investors expect the present financial market is in a relatively stable and optimistic state. On the contrary, when investors feel pessimistic or panic about the situation of present financial market, the numeric value of $V I X_{t}$ goes high. As such, in the regime 1 where the $V I X_{t}$ is smaller than the threshold value of 23.602, it represents investors expect the present economy or financial market is in a relatively optimistic state. While in the opposite situation, the regime 2 where the $V I X_{t}$ is greater than 23.602 indicates that in a relatively pessimistic state.

Secondly, for the interest rate spread IRS in this study, it is often observed that the interest rate is usually high when the economy is booming, and it is often low when the economy is depressed. When investors expect the situation of present economy is better than that in the future, the IRS will be usually small. Especially, the IRS is inverted when investors expect that the situation of economy in the future will be very depressed. Therefore, the regime 1 indicates that investors expect the present economy of the US (the China) is in a relatively optimistic state when the spread of $I R S_{U S}\left(I R S_{C N Y}\right)$ is smaller than $1.76 \%(0.6 \%)$. On the contrary, on the other side, the regime 2 indicates that investors expect the present economy is in a relatively pessimistic state, while that in the future is relatively optimistic. 
switching market-level exposures; this should motivate future research and more formal investigations.

\section{REFERENCES}

[1] Adler, M., Dumas, B. 1984. Exposure to Currency Risk: Definition and Measurement. Financial Management 13 (2), 41-50.

[2] Bartram, S. M., 2004. Linear and Nonlinear Foreign Exchange Rate Exposures of German Nonfinancial Corporations. Journal of International Money and Finance 23 (4), 673-699.

[3] Béreau, S., Villavicencio, A.L., Mignon, V., 2010. Nonlinear Adjustment of the Real Exchange Rate towards its Equilibrium Value: A Panel Smooth Transition Error Correction Modeling. Economic Modelling 27 (1), 404-416.

[4] Chue, T. K., Cook, D., 2008. Emerging Market Exchange Rate Exposure. Journal of Banking and Finance 32 (7), 1349-1362.

[5] Dominguez, K. M. E., Tesar, L.L., 2006. Exchange Rate Exposure Journal of International Economics 68 (1), 188-218.

[6] Friberg, R., Nydahl, S., 1999. Openness and the Exchange Rate Exposure of National Stock Markets. International Journal of Finance and Economics 4 (1), 55-62.

[7] González, A., Teräsvirta, T., van Dijk, D., 2005. Panel Smooth Transition Regression Models. Working Paper Series in Economics and Finance No. 604

[8] González, A., Teräsvirta, T., van Dijk, D., Yukai Yang. 2017. Panel Smooth Transition Regression Models. Creates Research Paper 201736.

[9] Hutson, E., O’Driscoll, A. 2010. Firm-level Exchange Rate Exposure in the Eurozone. International Business Review 19 (5), 468-478.

[10] Jorion, P., 1990. The Exchange-rate Exposure of US Multinationals Journal of Business 63 (3), 331-345.

[11] Koutmos, G., Martin, A. D., 2003. Asymmetric Exchange Rate Exposure: Theory and Evidence. Journal of International Money and Finance 22 (3), 365-383.

[12] Levi, M. D., 1994. Exchange Rates and the Valuation of Firms. In Amihud, Y., Levich, R.M. (Eds.), Exchange Rates and Corporate Performance. Irwin, New York, pp. 37-48.

[13] Muller, A. and Verschoor, W. F. C., 2006. Foreign Exchange Risk Exposure: Survey and Suggestions. Journal of Multinational Financial Management 16, 385-410.

[14] Muller, A. and Verschoor, W.F.C., 2007. Asian Foreign Exchange Risk Exposure. Journal of the Japanese and International Economics 21 (1), 16-37.

[15] Parsley, D. C., Popper, H. A., 2006. Exchange Rate Pegs and Foreign Exchange Exposure in East and South East Asia. Journal of International Money and Finance 25 (6), 992-1009.

[16] Priestley, R., Ødegaard, B. A., 2007. Linear and Nonlinear Exchange Rate Exposure. Journal of International Money and Finance 26 (6), 1016-1037.

[17] Solakoglu, M. N., 2010. Exchange Rate Exposure and Real Exports. Applied Economics Letters 17 (5), 457-462.

[18] Williamson, R., 2001. Exchange Rate Exposure and Competition Evidence from the Automotive Industry. Journal of Financial Economics 59 (3), 441-475. investors' pessimistic expectation of the present economy occurs, this portfolio of exposure risk inverts to the upper region where the exposure against the USD becomes plus and that against the CNY becomes minus. Overall, by the PSTR-ECM framework, this study reveals more information about the evolving process of exposures and demonstrates that the foreign exchange rate exposures are regimeswitching.

Finally, this study has presented an original empirical model which identifies the nonlinear features of regime- 